\title{
Pikaia (http://www.pikaia.eu): A New Way to Inform on Evolution in Italy
}

\author{
Paolo Coccia • Mauro Mandrioli • Chiara Ceci • \\ Telmo Pievani
}

Published online: 13 September 2008

(C) Springer Science + Business Media, LLC 2008

\begin{abstract}
Since 2005 the website Pikaia (http://www. pikaia.eu) is active in Italy keeping Italian readers informed about everything new happening in the fields of evolution in Italy and abroad and suggesting news, papers, books, websites, congresses and seminars.
\end{abstract}

Keywords Evolution·Pikaia $\cdot$ Italy

\section{Evolution Acceptance in Italy}

According to the last international survey about the public acceptance of evolution (Miller et al. 2006), more than $60 \%$ of Italian citizens think that the theory of evolution is correct and verified. This result could sound good if compared to USA, where less than $40 \%$ of the citizens accept the theory of evolution, but is below the expected

P. Coccia $\cdot$ C. Ceci

Italian Association of "Documentalisti Industria Farmaceutica", Milan, Italy

M. Mandrioli

Department Animal Biology,

University of Modena and Reggio Emilia,

Modena, Italy

C. Ceci $\cdot$ T. Pievani

Department of Human Sciences for Education,

University of Milan Bicocca,

Milan, Italy

M. Mandrioli $(\bowtie)$

Dipartimento di Biologia Animale,

Università di Modena e Reggio Emilia,

Via Campi 213/d,

41100 Modena, Italy

e-mail: mandrioli.mauro@unimo.it standard for a theory that is confirmed well beyond the shadow of a doubt. For instance, the Italian acceptance of evolution is lower than that observed in north Europe, where it is over than $80 \%$ in some countries (such as Iceland, Denmark, and Sweden).

In recent years, an increasing number of amateurish books and papers has been published in Italy against the Darwinian theory, according to a spread of criticisms against evolution, frequently related to the politicization of religious values.

The concern about this phenomenon is hampered in Italy, since in 2004 the Darwinian theory was astonishingly deleted from the curricula of the school courses in sciences, leading to a public remonstrance that resulted in a partial (and actually inadequate) reintroduction of Darwin in the outlines (Pievani 2007).

At the same time, a similar trend has been observed in other European countries prompting the Committee on Culture, Science and Education of the Parliamentary Assembly of the Council of Europe to adopt in October 2007 a resolution (Resolution 1580, Parliamentary Assembly of Council of Europe 2007) about the dangers of creationism in education. In particular, as reported in the resolution, in Europe "we are witnessing a growth of modes of thought which, the better to impose religious dogma, are attacking the very core of the knowledge that we have patiently built up on nature, evolution, our origins and our place in the universe."

In view of this nonscientific criticism against the theory of evolution, the availability of resources for improving public understanding of evolution and teaching at school is extremely important, and considering that three of the four Italian members of the European Committee on Culture, Science and Education voted against this resolution, this could be particularly true for Italy. 
In this context, the website Pikaia (http://www.pikaia.eu) has been active in Italy since 2005, with the main aim of keeping Italian readers informed about everything regarding evolutionary biology happening in Italy and abroad.

\section{Pikaia: Origins and Structure of the Website}

The website Pikaia (ISSN 1827-8647) takes its name from Pikaia gracilens, an extinct animal found near Mount Pika in the Burgess Shale of the British Columbia, which represents the earliest known ancestor of all chordates, as reported by Stephen J. Gould in 1989 in his book Wonderful Life: The Burgess Shale and the Nature of History. The choice of this name is a way to pay homage to our earliest ancestor and, at the same time, to Stephen J. Gould, whose works greatly improved our comprehension of evolution.

Pikaia, which takes its origin from a pre-existing blog (http://darwininitalia.blogspot.com) through the collaboration between Telmo Pievani and Paolo Coccia, currently publishes the latest news on evolution on a daily basis in order to

\section{darwikinitit Pikaia il portale dellevoluzione}
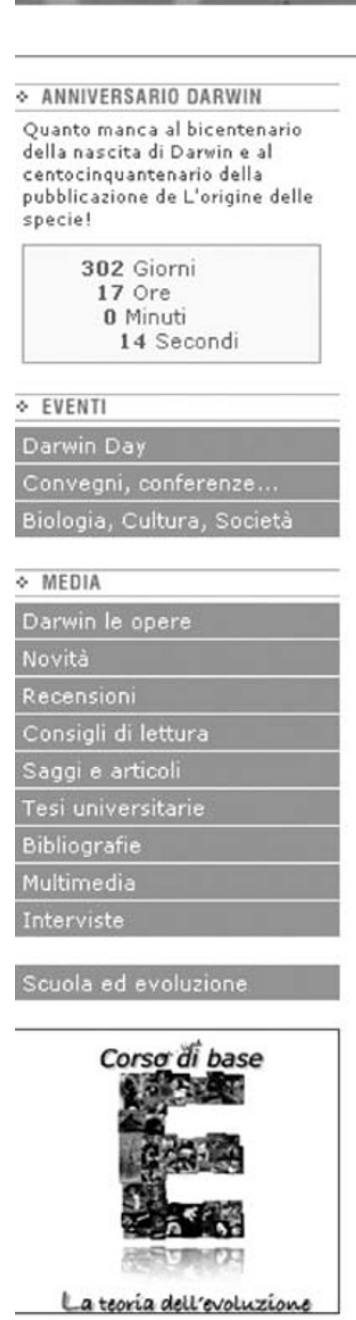

HOME ISSN $1827-8647$ PRESENTAZIONE CHI SIAMO COPYRIGHT

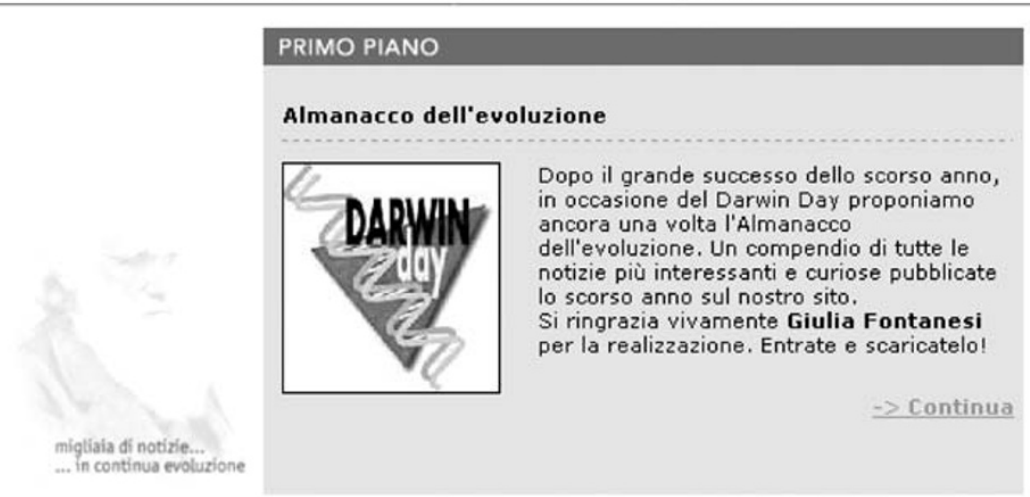

\section{NEWS}

15/04/2008 :: Omaggio a Gould Bibliografie

Bibliografia delle opere di S.J. Gould tradotte in italiano. Versione aprile 2008 Ho aggiunto la seguente citazione bibliografica:

Lewontin, Richard C., 2008. Il trionfo di Stephen Jay Gould. Recensione ai volumi di Stephen Jay Gould, The Richness of Life: The Essential Stephen Jay Gould, a cura di Steven Rose, con un'introduzione di Oliver Sacks, New York, Norton e Punctuated Equilibrium, Cambridge (MA), Belknap Press/Harvard University Press. La Rivista dei Libri, Marzo 2008

\section{Paolo Coccia} $\Rightarrow$ Continua

14/04/2008 :: Botanica e Zoologia

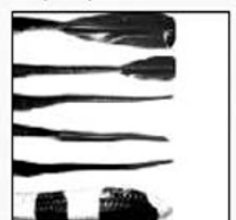

\section{alla terra alle acque}

Una modificazione anatomica che conferisce un vantaggio in un ambiente, spesso potrebbe imporre un costo in un altro. Un interessante studio sperimentale sulla transizione tra terra e acqua.

\section{.}
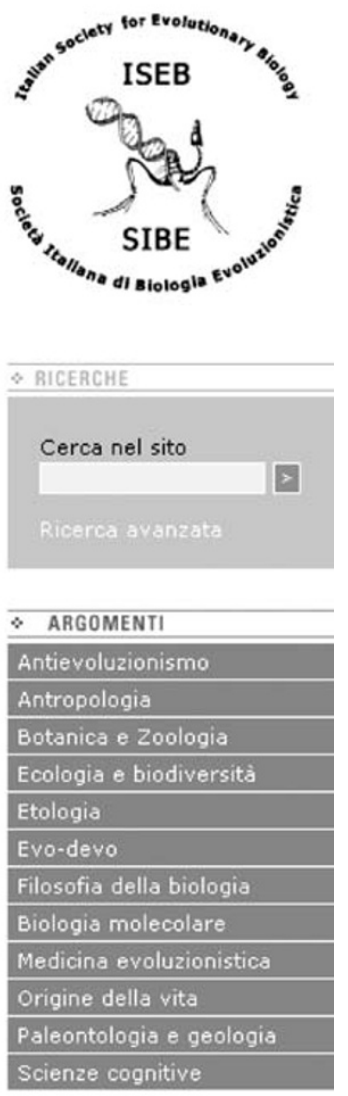

$-$

\begin{tabular}{l}
\hline LE NOSTRE PUBBLICAZIONI \\
\hline Glossario \\
\hline Omaggio a Gould \\
\hline Immaginari \& evoluzione \\
\hline
\end{tabular}

Fig. 1 Pikaia consists in a central portion containing a section reporting the latest news about papers, events, and books and a foreground section specifically presenting highly interesting essays or commentary. On the left, a list of links allows readers to easily find programs of the Italian Darwin Day, seminars and congresses on evolutionary biology, and different links to book reviews, essays, multimedia files, and interviews. On the right, readers can find the old published news subdivided in different categories (i.e., anthropology, zoology, evo-devo, evolutionary medicine, history of evolution) and easy access to the Stephen J. Gould section 
fill the gap existing in the Italian mass media, where no journals or websites are specifically devoted to natural history. Moreover, Pikaia keeps informed and updated the readers (mainly teachers, students, and academic personnel) interested in evolutionary subjects by presenting the most interesting books, papers, and events on evolution ranging from molecular evolution to ethology, including not only human but also plant and animal evolution.

In order to properly address the different research fields that are part of evolutionary biology, the editorial staff consists of academic scientists (whose expertise ranges from genetics and anthropology to science history and philosophy), museum experts, and specialists in science communication who work for Italian journals and who can assure both quality and readability. Moreover, the Pikaia editorial staff also includes schoolteachers who may evaluate the quality of the resources suggested for school together with developing new resources for school pupils.

Pikaia also publishes short essays and commentary on specific topics related to evolution that can be written by members of the editorial staff or by invited scientists. Pikaia continuously suggests new websites, links, and journals or teaching proposals with particular interest for those that are freely available for readers.

At present, Pikaia is collaborating with different Italian Institutions involved in science education (such as museums, i.e., the Natural History Museum of Milan, and scientific associations, i.e., the Italian Society of Evolutionary Biology, http://www.sibe-iseb.it) in order to support the materials available in the web with lectures and projects that take place during different national events of communication of science (such as the Genoa Science Festival and the Darwin Day in Milan).

In the last years, Pikaia strongly increased its own visitors now consisting of about 15,000 unique ID contacts a month, and it has been recently updated in order to improve readability and to make Pikaia a more user-friendly tool for recovering information and news on evolution and natural sciences.

Pikaia readers may submit comments or questions by email contacting the editor-in-chief, who may reply directly or redirect the message to a member of the editorial staff whose expertise may address the reader's questions.

Pikaia (Fig. 1) can be a friendly read for web users since it consists in a central section reporting the latest news on papers, events, and books and in two link sections that allow readers to find the old news subdivided in different categories (i.e., anthropology, zoology, evo-devo, evolu- tionary medicine, history of evolution) and to easily find the last cited events (i.e., Darwin Day programs, conferences, seminars) and books.

A section has been permanently dedicated to Stephen J. Gould, where users can find, browse, and read news about the last papers published about Gould's work as a scientist and science writer and download the most complete and updated Italian bibliography on his publications (books, articles, comments, editorial, etc.).

Pikaia, which is freely available for readers, is currently sustained by grants from Universities (University of Milan Bicocca and University of Modena and Reggio Emilia) and by a special program for the diffusion of scientific knowledge promoted by the Italian Ministry of University.

\section{Future Developments}

New Pikaia sections will be available in the near future with particular attention to multimedia that will allow users to follow events in streaming (as recently done for the Darwin Day 2008 in Milan) or as podcast files. In particular, Pikaia will host a new section containing audio files about new papers or books of particular interest for evolutionary biology, museum exhibitions, lectures, and seminars about evolution, and the development of an audio introductory guide for beginners about evolution will start in the near future.

Shortly, Pikaia readers will have the possibility of activating an RSS feeder in order to be informed about Pikaia updating.

Finally, Pikaia will start collaboration with other websites, such as Videoscienza (http://www.videoscienza. it), which publish videos or other multimedia files that may represent a precious resource for evolutionary biologist and students.

\section{References}

Miller JD, Scott EC, Okamoto S. Public acceptance of evolution. Science 2006;313:765-6.

Parliamentary Assembly of Council of Europe (2007) The dangers of creationism in education. Resolution 1580. Doc. 11375, report of the Committee on Culture, Science and Education. Available at: http://assembly.coe.int/Main.asp?link=/Documents/Adopted Text/ta07/ERES1580.htm.

Pievani T. In difesa di Darwin. Piccolo bestiario dell'antievoluzionismo all'Italiana. Italy: Bompiani; 2007. p. 128. 